\title{
PROCESSOS DE ALFABETIZAÇÃO E A CRIANÇA DE SEIS ANOS NO ENSINO FUNDAMENTAL: DESAFIOS CONTEMPORÂNEOS ${ }^{1}$
}

\author{
LITERACY PROCESSES AND THE SIX-YEAR-OLD CHILD \\ IN ELEMENTARY SCHOOL: CONTEMPORARY THREATS
}

\author{
AGUIAR, Maria Aparecida Lapa de \\ lapa.aguiar@ufsc.br \\ Universidade Federal de Santa Catarina - UFSC
}

\begin{abstract}
RESUMO O artigo apresenta resultados parciais de pesquisa relacionada à inserção da criança de seis anos no ensino fundamental e que vem sendo realizada junto a uma rede de ensino de um município do sul do país, com o objetivo central de verificar como essa rede vem se organizando para o atendimento das crianças de seis anos no ensino fundamental. Entre os procedimentos metodológicos está a observação de classes de $1^{\circ}$ ano, cujas responsáveis são professoras indicadas pela Secretaria de Educação como protagonistas de experiências bem sucedidas, e a realização de entrevistas com esses sujeitos, a fim de averiguar como a professora concebe o processo de alfabetização a partir da entrada da criança de seis anos no ensino fundamental. Neste artigo, será analisada uma entrevista realizada com uma das professoras participantes da pesquisa, com a intenção de contribuir para a compreensão sobre como a inclusão dessas crianças vem ocorrendo no interior da escola e sobre qual o papel da formação continuada oferecida pela rede na atuação das professoras responsáveis por essas classes.
\end{abstract}

Palavras-chave: Ensino fundamental. Criança de seis anos. Alfabetização

ABSTRACT The article presents the partial results related to the insertion of a sixyear-old in elementary school and has been realized together with a chain of schools in the south of the country with the objective of verifying how this chain is organized in order to receive six-year-old children in elementary school. Among the methodology procedures is the observation of classes from the first grade, whose responsible are teacher indicated by the Secretary of Education as protagonists of successful experiences and the realization of interviews with such subjects in order to verify how the teacher conceives the literacy process from the entry of a six-yearold child in fundamental school. In this article an interview will be analyzed with one of the teachers participating in the research in order to contribute to the comprehension of how the inclusion of these children has been occurring inside the

\footnotetext{
${ }^{1}$ Este texto foi apresentado originalmente como trabalho em Painel do XVI ENDIPE (Campinas/SP: 23 a 26 de julho de 2012).
} 
school and about what is the role of continuous formation offered by the chain in the performance of the teachers responsible for these classes.

Keywords: Elementary school. Six-year-old child. Literacy.

\section{INTRODUÇÃO}

As reflexões em torno da alfabetização e da formação da professora alfabetizadora vêm compondo a nossa trajetória de pesquisa há vários anos em diferentes momentos da carreira profissional: como professora em redes de ensino fundamental, durante pesquisa realizada na especialização, trabalhando com formação de professores em serviço e com pesquisa voltada para a área de formação de alfabetizadoras durante o doutorado.

A demanda legal posta para a escola brasileira ampliou o ensino fundamental para nove anos com a entrada da criança de seis anos (Leis no 11.114 de 2005 e $n^{\circ}$ 11.274 de 2006 que dão nova redação a alguns artigos da LDB de 1996). Em virtude dessas modificações, o Ministério da Educação organizou várias obras voltadas para a inclusão da criança de seis anos no processo de escolarização formal que visam subsidiar tais discussões.

Dentre os documentos publicados pelo MEC estão: "Ensino Fundamental de Nove Anos: orientação para a criança de seis anos de idade" (BRASIL, 2007), que contempla textos de autores/pesquisadores da área da infância e linguagem, como por exemplo, Sonia Kramer, Cecília Goulart e Telma Ferraz Leal. Há de se mencionar também outra publicação que traz diretrizes sobre a normatização e organização pedagógica necessárias para a implantação dos noves anos no Ensino Fundamental: "Ensino Fundamental de nove anos: passo a passo do processo de implantação" (BRASIL, 2009). Merece menção ainda a obra organizada por Francisca Maciel, Mônica Baptista e Sara Monteiro e intitulada "A criança de 6 anos, a linguagem escrita e o ensino fundamental de nove anos: orientações para 0 trabalho com a linguagem escrita em turmas de crianças de seis anos de idade" (2009) e "Acervos complementares: as áreas do conhecimento nos dois primeiros anos do Ensino Fundamental" (BRASIL, 2009) que diz respeito a uma orientação do uso dos livros do Programa Nacional do Livro Didático (PNLD). 
Neste artigo, especificamente, apresentaremos resultados parciais de pesquisa sobre a inserção da criança de seis anos no ensino fundamental, vinculada a grupos de pesquisa dos quais participamos junto à universidade em que atuamos. Temos Investigado desde o início de 2011 como a rede de um município do sul do país vem se organizando para o atendimento das crianças de seis anos no ensino fundamental. Dentre os objetivos que pretendemos alcançar estão: analisar os documentos federais e municipais direcionados para a inclusão das crianças de seis anos no ensino fundamental; verificar como a inclusão dessas crianças ocorre no interior de duas escolas consideradas bem sucedidas nessa tarefa e investigar qual o papel da formação continuada oferecida pela rede na atuação das professoras responsáveis pelas classes de crianças de 6 anos dessas escolas.

No que diz respeito aos procedimentos metodológicos, iniciamos com um estudo dos documentos oficiais destinados à orientação e legalização da inclusão das crianças de seis anos no ensino fundamental (realizado no início do projeto de pesquisa).

No decorrer do ano de 2011, assistimos a aulas da primeira professora indicada pela Secretaria de Educação considerada como experiência bem sucedida, realizamos uma entrevista e acompanhamos a formação oferecida pela rede de ensino a fim de verificar como vem se dando a organização para a inclusão da criança de seis anos no ensino fundamental, tanto na formação continuada, quanto no interior da escola.

Este artigo está focado na entrevista realizada com uma das professoras, sujeito da pesquisa, após observações de sala de aula. Explicitaremos, portanto, algumas considerações sobre sua formação e seus encaminhamentos teóricometodológicos em uma turma de crianças de seis anos. A intenção é que essa investigação contribua para ampliar a reflexão sobre infância, alfabetização, processos de escolarização e formação continuada.

\section{A PROFESSORA SUJEITO DA PESQUISA E OS PROCESSOS DE ALFABETIZAÇÃO}


Uma das docentes indicadas pela Secretaria da Educação do Município atua em uma escola de pequeno porte que tem aproximadamente 150 crianças. Do pátio de entrada da escola avista-se uma quadra de esportes pequena, poucas salas de aula, a sala da direção, a cozinha, um refeitório aberto e nos fundos da escola, uma horta e a biblioteca numa construção anexa em que também funciona uma sala de informática. Os ambientes são pequenos, mas comportam com certa tranqüilidade o número de crianças. A direção e algumas professoras mencionaram a possibilidade de reformas e ampliações futuras.

$\mathrm{Na}$ sala observada havia 23 crianças, a maioria com seis anos e algumas delas já com sete anos. Trata-se de um espaço também pequeno e com algumas características de sala de educação infantil. No fundo da sala havia lugar para as mochilas e alguns brinquedos. Na sala havia também um quadro para giz, cartazes de números e representação de quantidades, alfabeto em vários formatos, calendário e os nomes das crianças. As carteiras e cadeiras estavam agrupadas em duplas e eram adequadas à altura das crianças, o que está de acordo com a Resolução da Rede de ensino de 2010 daquele município que fixa normas para o Ensino Fundamental de 09 (nove) anos, quando menciona no artigo $5^{\circ}$, parágrafo $5^{\circ}$ que: "A Secretaria Municipal de Educação deverá em conjunto com as unidades educativas, adaptar sua estrutura física criando novos espaços para os estudantes".

A professora Rose (nome fictício) se formou em 1987 no magistério (Nível Médio) e em Pedagogia com habilitação em Supervisão Escolar em 1994 e atua há 22 anos e meio na Educação, sendo que a maior parte deles (20 anos praticamente) com o primeiro ano de escolarização. Quando lhe perguntamos como tem sido trabalhar com as crianças de 6 anos, no primeiro ano do ensino fundamental, ela nos respondeu:

Entrev. Rose: Bom, a questão de maturidade, a gente percebe bastante a dificuldade, por que as crianças elas... antes quando eram os de 7 anos a gente via, eles tinham mais facilidade de entrar em ritmos em ... na questão disciplinar, de atividades, de concentração, e as crianças de 6 anos, elas têm uma concentração, digamos assim, mais limitada, eu percebo que eles têm a necessidade muito mais de brincar, da questão do lúdico, que têm essa necessidade que, não que os de 7 anos não tinham, mas eles sentem mais essa ausência, que antes eles na educação infantil, eles tinham mais tempo do que agora. Por causa de todas as atribuições que têm na questão da alfabetização, mas, por mais que a gente tenha as atividades voltadas também para o lúdico, a questão do parque, a questão de atividades livres 
que eles têm na educação infantil, daquele momento que... porque aqui na nossa unidade tem isso, na educação infantil, eles têm momentos livres na sala de aula, coisa que nós do ensino fundamental fica um pouco mais difícil deles terem essas questões mais livres, nós temos durante a semana, aí na nossa grade, não é grade, na nossa agenda semanal, eu cheguei a organizar então momentos em que eles têm do brinquedo e do parque, por causa desta necessidade mesmo, então a gente fez essa adaptação, por causa da necessidade das crianças.

A professora, mesmo com toda a sua experiência na área de alfabetização, reconhece as dificuldades de lidar com as crianças de seis anos nesse primeiro momento e sinaliza a necessidade delas próprias de ter espaços e tempos diferenciados característicos da educação infantil. Ficou perceptível o empenho da rede, da escola e da professora em fazer adaptações para essa transição, mesmo com as dificuldades de conciliar a demanda que vem impregnada no modo de ser do ensino fundamental que parece esquecer que sua função primeira é lidar com crianças e suas singularidades no aprender e no brincar.

Perguntamos em seguida se Rose teria recebido alguma formação especifica da rede municipal para atuação com as crianças de 6 anos, e assim respondeu:

Entrev. Rose: Sim, desde quando veio a lei, a partir de 2008, a prefeitura, ela já vem proporcionando esses encontros, com os professores de primeiro ano, e já pensando nessa questão, desse ambiente, da própria metodologia de trabalho, então a formação já vem focada também para essas crianças.

Rose demonstra estar comprometida e integrada nos processos de mudanças e adaptações propostos pela Rede Municipal e ratifica que vem recebendo formação para este fim.

Seguimos questionando se a escola recebeu alguma orientação em relação ao tratamento a essas crianças, se havia alterado a organização da sala de aula, mobiliário ou algum outro procedimento nesse sentido. E a professora respondeu:

Entrev. Rose: Sim. Nós, até chegamos a ter as mobílias de mesas onde eram seis crianças na mesma mesa, mas, como nós atendemos primeiro ano e segundo ano, às vezes primeiro ano e terceiro ano, no mesmo ambiente, ficou difícil de nós mantermos essa organização, então nós optamos por cadeiras... mobiliários individuais menores do que os maiores usam, mas a organização então, dessas mobílias individuais é que eu modifico. Então, às vezes mantenho elas em "U", ou faço em trios, ou em duplas, às vezes individuais. Então a cada um ou dois meses eu faço essa modificação desse mobiliário e também nós organizamos no fundo da sala, tapetes porque as crianças... aí temos bonecas, carrinhos, temos o canto 
que tem dos livros, os gibis que antes nós não tínhamos, então nós até pensamos nessa organização pra essas crianças.

Rose conta sobre a organização da sala pensada para essa criança de seis anos que se baseia no modo de ser da organização da educação infantil: mobiliário adequado aos tamanhos das crianças, outras formas de organização (mesinhas de seis cadeiras, carteiras em formação de grupos, espaço para brincar...). Entretanto, a escola continua com tendência ao trabalho individualizado, pois para as crianças maiores de sete anos os encaminhamentos são pensados de outras maneiras, as formas tradicionais de ocupação do tempo e espaço da escola prevalecem.

Após essas considerações, perguntamos como a professora alfabetiza e assim ela relatou:

\begin{abstract}
Entrev. Rose: Nós partimos sempre da questão do "eu", o nome... nós apresentamos o alfabeto e o foco na alfabetização vem pelo fonema, então a gente vai trabalhando as letras, mas essas letras dentro de um contexto que daí são os nomes, ou que são músicas, ou poemas, dentro da própria literatura com histórias, então a gente vai trabalhando as letras do alfabeto, focando a questão dos fonemas, então, isso é muito forte, quando a gente vai pronunciar as palavras, a gente dá ênfase àquelas letras que estamos trabalhando, para que elas sejam fixadas tanto no fonema quanto grafema dessas palavras.
\end{abstract}

Nas aulas que assistimos ficou nítido todo o processo descrito anteriormente, as crianças eram envolvidas pela professora em práticas sociais de leitura e escrita - alfabetização com letramento - como, por exemplo, na organização de um relatório a partir dos registros sobre o projeto de uma horta escolar. A professora, na condição de escriba, provocava as crianças a pensarem como iriam fazer o registro. Suas mediações com perguntas, informações e reflexões traziam à memória o que haviam vivenciado e ao mesmo tempo as questões relacionadas ao sistema de escrita iam sendo trabalhadas com ênfase nos grafemas e fonemas. As crianças demonstravam envolvimento, interesse e participavam ativamente. Ficou evidente na fala da professora e no decorrer de suas aulas que "as crianças não se apropriam dos resultados do desenvolvimento histórico imediatamente. Esse processo é mediado pelas relações com as outras pessoas no decorrer de sua vida" (GONTIJO, 2003, p. 16). 
Questionamos também se essas crianças de seis anos chegavam alfabetizadas na escola e ela nos respondeu:

Entrev. Rose: É assim, geralmente nós temos entre a turma algumas crianças que já estão, que já conhecem o alfabeto, algumas já estão lendo palavras, então, no início do ano é comum, num universo de 25 crianças, que é o que a gente teve, esse ano eu tive isso..., de 25 crianças 2 ou 3 que já conseguiam ler algumas palavras... a maioria... eu tive a maioria que conheciam algumas letras, e aí foram no decorrer do tempo se apropriando das letras do alfabeto e fazendo junção e reconhecendo elas, e agora fazendo a leitura. Hoje eu tenho metade da turma, lendo. Então, antes dessas duas crianças que eu tinha, lendo algumas palavras no começo do ano, não eram todas.

Nessa fala de Rose fica clara a realidade das classes de alfabetização. A complexidade desse momento exige muito esforço da parte da professora e das crianças. O ambiente alfabetizador vai se construindo com mediações e a consciência sobre a necessidade da apropriação da escrita vai sendo gerada juntamente com a sua compreensão. Nas palavras de Gontijo (2003, p. 148-149),

É preciso acentuar que o ensino da linguagem escrita, na fase inicial da alfabetização, deve articular os dois planos da linguagem: sonoro e semântico, pois estes são os seus constituintes essenciais. É necessário ter em mente que a função do signo, da linguagem escrita, é significar. As significações só existem no terreno interlocutivo. Dessa maneira é fundamental que a escrita esteja dirigida às pessoas, possibilitando o diálogo e a interação entre os indivíduos. Só assim será incorporada pelas crianças como atividade social, resultado da vida social das gerações passadas - como produção humana.

Em seguida, questionamos sobre o que contribuiu para que ela fosse a alfabetizadora que é, visto que, em nossas observações em sala de aula, pudemos perceber a segurança, a facilidade de mediações provocativas que fazia com que as crianças estivessem envolvidas no processo de alfabetização formal de maneira bastante efetiva. Assim ela se manifestou:

Entrev. Rose: Eu acho que a experiência é a grande responsável, hoje o resultado desse... de tudo que tenho hoje do meu trabalho, vem do dia a dia mesmo. Claro que leituras, mas assim, o que que a gente faz? A gente lê, vai na formação e coloca na prática, a análise desta prática, é que vai fazer com que tu faças um bom trabalho, por que se tu só pegar aquilo ali, aplicar e não refletir sobre o resultado disso... porque já teve momentos em que nós aplicamos em que não deu certo, e essa reflexão do que não deu certo 
é que fez avançar, então, é essa prática mesmo do ir e vir mesmo é que faz que tenhamos um resultado futuramente melhor.

Ela ilustra sua explicação com um exemplo:

\begin{abstract}
Entrev. Rose: Porque, por exemplo, eu tive um ano com o segundo, e aí como exemplo de reflexão, teve um ano em que eu comecei com letra cursiva no segundo ano já no início de ano, e aí eu compliquei a cabeça das crianças, porque eles não tinham o domínio ainda da escrita. Porque eles recém tinham feito um primeiro ano, não tinham o domínio da escrita ainda, nem com a letra na caixa alta e tal, e eu já apresentei outro código, ...uma outra forma do código, aí eu vi que eu desestruturei a turma, então, eu percebi já pros próximos anos que eu não poderia estar fazendo isso, que eu teria que estar resgatando, eu resgatei um pouco, mas logo em seguida eu entrei. Então teriam que estar bem firmes e seguros, dentro dessa escrita desse alfabeto, pra apresentar numa outra letra de um outro formato e aí eles terem condições, e até mesmo pra eles, assim, oh, a letra cursiva conhecer que ela existe, saber ler, saber escrever mas dar a opção pra eles, qual é a letra que eles melhor conseguem se comunicar. Sabe, então, isso hoje eu a partir de uma reflexão, isso eu percebo, que, o ideal é isso, é tu apresentar um trabalho com a letra cursiva no segundo ano, porque eles têm, faz parte, eles têm que saber ler e saber escrever com todas as letras, mas tu deixar eles livres, porque se eles têm um domínio maior com uma letra em maiúscula script ou em minúscula script, ou na letra cursiva, eles escolhem e aí vai ser muito mais fácil, muito mais prático pra eles, deles fazerem, deles seguirem na hora de copiar por exemplo um texto que tenha, se ele tem muito mais facilidade com a cursiva, que faça com a cursiva, ou com a outra, que faça com a outra. Se eles conseguem então.
\end{abstract}

A professora menciona a experiência como eixo principal de seu trabalho. Entretanto, cita também formação recebida e leituras, o que evidencia que a experiência a ajuda nas reflexões que faz a cada ano com cada nova turma, mas há de se considerar que essa é alimentada por aprendizados diversos em cursos, em leituras, em trocas com pares, observando o andamento das crianças, suas formas de conceber o mundo da escrita e tudo isso vai compondo o seu modo de ser professora, sua organização didático-pedagógica e, tendo ou não consciência sobre isso, a professora vai se formando ao longo de seu trajeto profissional. Como lembra Tardif (2002, p. 36) "Pode-se definir o saber docente como um saber plural, formado pelo amálgama, mais ou menos coerente, de saberes oriundos da formação profissional e de saberes disciplinares, curriculares e experienciais".

Nossas análises, a partir da fala da professora, levam a pensar nas escolas e na forma como são organizadas. Pelo que pudemos verificar, por essa e outras pesquisas desenvolvidas, os espaços/tempos de formação em serviço ainda são 
reduzidos, na maioria das vezes restringem-se a algumas reuniões pedagógicas e encontros bimestrais oferecidos pela secretaria de educação. O tempo dedicado às reflexões sobre o fazer pedagógico ocorre geralmente fora dos espaços da escola, de maneira solitária e informal.

Ainda temos muitos passos a dar em direção a uma formação que se faça a partir do cotidiano de nossas realidades escolares. Acolher essas crianças que cada vez entram mais cedo nos ambientes de escolarização é um desafio para o educador que não poderá fazer esse caminho adequadamente sem uma política de formação permanente que transpasse as escolas e os envolva.

\section{CONSIDERAÇÕES FINAIS}

As reflexões presentes neste artigo evidenciam um dos desafios que se colocam para a escola na contemporaneidade: a inclusão da criança de seis anos no ensino fundamental. Pensar sobre esse processo induz a uma necessária reflexão sobre infância, alfabetização, processos de escolarização e formação continuada.

As palavras de Kramer (2006, p. 810) ilustram essa demanda atual:

Com a Lei n. 11.274/2006, o ensino fundamental passa a ter nove anos, no Brasil, e inclui obrigatoriamente as crianças de 6 anos, o que já é feito em vários países e em alguns municípios brasileiros há muito tempo. Mas muitos professores ainda perguntam: $O$ melhor é que elas estejam na educação infantil ou no ensino fundamental? Meu ponto de vista é o de que o planejamento e o acompanhamento pelos adultos que atuam na educação infantil e no ensino fundamental devem levar em conta a singularidade das ações infantis e o direito à brincadeira, à produção cultural, na educação infantil e no ensino fundamental. Isso significa que as crianças devem ser atendidas nas suas necessidades (a de aprender e a de brincar) e que tanto na educação infantil quanto no ensino fundamental sejamos capazes de ver, entender e lidar com as crianças como crianças e não só como alunos. A inclusão de crianças de 6 anos no ensino fundamental requer diálogo entre educação infantil e ensino fundamental, diálogo institucional e pedagógico, dentro da escola e entre as escolas, com alternativas curriculares claras.

O reconhecimento de que a criança é um ser de direitos e dentre esses está a apropriação da linguagem escrita e da leitura coloca sobre a escola a responsabilidade de um diálogo com muitas vertentes: sobre formação dessa alfabetizadora, sobre quem é a criança brasileira de nossas escolas públicas e sobre 
como pensar a infância nesse cotidiano. Concordamos com Kramer, Nunes e Corsino (2011, p. 82), quando afirmam que:

\begin{abstract}
A escolarização está pautada em um modelo de conhecimento que cinde ciência, arte e vida e no controle do conhecimento, com propostas de soluções prefixadas e previsíveis. É urgente que as práticas pedagógicas na educação infantil e no ensino fundamental se desloquem desse modelo e favoreçam a construção de significados singulares não só previamente determinados, mas constituídos nos acontecimentos da história. E que sejam delineadas estratégias de transição entre as etapas, cuja omissão se constitui em grave problema. Atuar nas transições pode contribuir para criar nas escolas de educação infantil e ensino fundamental espaços para a prosa do dia a dia, onde as narrativas tecidas favoreçam os nexos, os sentidos, as mudanças institucionais e pessoais.
\end{abstract}

As instituições educativas, em sua maioria, ainda se constituem por processos marcados por uma tradição que cinde a infância, que não consegue lidar com tranquilidade com a real necessidade de familiarizar as novas gerações com o mundo da escrita e tudo o que dele decorre. E por fim, lidamos ainda com o desafio da formação continuada do professor que merece ter seus espaços e tempos ampliados para uma reflexão formal e consequente sobre todas as dimensões que envolvem o trabalho docente.

\title{
MARIA APARECIDA LAPA DE AGUIAR
}

Doutora em Educação pela Universidade Federal de Santa Catarina (UFSC). Professora do Departamento de Estudos Especializados em Educação do Centro de Ciências da Educação da Universidade Federal de Santa Catarina (CED/UFSC) e subcoordenadora do Curso de Pedagogia desta mesma instituição.

\section{REFERÊNCIAS}

BRASIL. Secretaria de Educação Básica. Acervos complementares: as áreas do conhecimento nos dois primeiros anos do Ensino Fundamental / Ministério da Educação, Secretaria de Educação Básica. - Brasília: MEC/SEB 2009. Disponível em:

http://portal.mec.gov.br/index.php?option=com content\&view=article\&id=15166\&ltem id=1130. Acesso em: 22 jan. 2011.

. Secretaria da Educação Básica. BEAUCHAMP, J.; / PAGEL, S. D.; NASCIMENTO, A. R. do (Orgs.). Ensino fundamental de nove anos: orientações para a inclusão da criança de seis anos de idade. Brasília: Ministério da Educação, Secretaria de Educação Básica, 2007. Disponível em: 
http://portal.mec.gov.br/index.php?option=com content\&view=article\&id=12624\%3A ensino-fundamental\&ltemid=859. Acesso em: 22 jan. 2011.

. Secretaria de Educação Básica. Ensino Fundamental de nove anos: passo a passo do processo de implantação. Ministério da Educação, Secretaria de Educação Básica. Diretoria de Concepções e Orientações Curriculares para Educação Básica (DCOCEB). Coordenação-Geral do Ensino Fundamental (COEF). Brasília: MEC/SEB 2009. Disponível em:

http://portal.mec.gov.br/dmdocuments/passo a passo versao atual 16 setembro. pdf. Acesso em: 22 jan. 2011.

. Ministério da Educação e Cultura. Lei de Diretrizes e Bases da Educação Nacional. Lei n. 9.394, de 20 de dezembro de 1996. Disponível em: http://www.planalto.gov.br/ccivil 03/Leis/L9394.htm> Acesso em: 23 jan. 2011.

. Ministério da Educação e Cultura. Lei n. 11.114, de 16 de maio de 2005. Altera os arts. 6o, 30, 32 e 87 da Lei n. 9.394, de 20 de dezembro de 1996, com o objetivo de tornar obrigatório o início do ensino fundamental aos seis anos de idade. Disponível em: http://www.planalto.gov.br/ccivil 03/ Ato20042006/2005/Lei/L11114.htm> Acesso em: 23 jan. 2011.

. Ministério da Educação e Cultura. Lei n. 11.274, de 6 de fevereiro de 2006. Altera a redação dos arts. 29, 30, 32 e 87 da Lei n. 9.394, de 20 de dezembro de 1996, que estabelece as diretrizes e bases da educação nacional, dispondo sobre a duração de 9 (nove) anos para o ensino fundamental, com matrícula obrigatória a partir dos 6 (seis) anos de idade. Disponível em:

<http://www.planalto.gov.br/ccivil 03/ Ato2004-2006/2006/Lei/L11274.htm> Acesso em: 23 jan. 2011.

. Secretaria da Educação Básica. MACIEL, F. I. P.; BAPTISTA, M. C.; MONTEIRO S. M. (orgs.). A criança de 6 anos, a linguagem escrita e o ensino fundamental de nove anos: orientações para o trabalho com a linguagem escrita em turmas de crianças de seis anos de idade. Belo Horizonte: UFMG/FaE/CEALE, 2009. Disponível em:

$<$ http://portal.mec.gov.br/index.php?option=com docman\&task=doc download\&gid= 4034\&ltemid>. Acesso em: 15 jan. 2011.

CONSELHO MUNICIPAL DE EDUCAÇÃO. Resolução n01/2010 fixa normas para o Ensino Fundamental de 09 (nove) anos da Rede Municipal de Ensino de Florianópolis, Santa Catarina.

$<$ http://www.pmf.sc.gov.br/arquivos/arquivos/pdf/11 072011 12.50.49.7a0271f876a 2810273c759afb8664688.pdf>. Acesso em: 22 jan. 2011.

GONTIJO, C.M.M. Alfabetização: a criança e a linguagem escrita. Campinas, SP: Autores Associados, 2003.

KRAMER, Sonia. As crianças de 0 a 6 anos nas políticas educacionais no Brasil: educação infantil e/é fundamental. Educ. Soc., Campinas, v. 27, n. 96, out. 2006. 
Disponível em <http://www.scielo.br/scielo.php?script=sci_arttext\&pid=S0101$73302006000300009 \&$ Ing=pt\&nrm=iso>. Acesso em 23 fev. 2012. http://dx.doi.org/10.1590/S0101-73302006000300009.

KRAMER, Sonia; NUNES, Maria Fernanda R.; CORSINO, Patrícia. Infância e crianças de 6 anos: desafios das transições na educação infantil e no ensino fundamental. Educ. Pesqui., São Paulo, v. 37, n. 1, abr. 2011 . Disponível em $<$ http://www.scielo.br/scielo.php?script=sci_arttext\&pid=S151797022011000100005\&lng=pt\&nrm=iso>. Acesso em 23 fev. 2012. http://dx.doi.org/10.1590/S1517-97022011000100005.

TARDIF, M. Saberes docentes e formação profissional. 7. ed. Petrópolis, RJ: Vozes, 2002. 